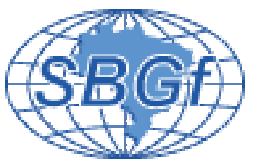

\title{
Nova Interpretação dos Dados de Refração Sísmica Profunda do setor Central da Província Tocantins Utilizando Ondas P, S e Reflexões de Ângulo Amplo - Modelo Preliminar
}

Fábio. A. Perosi* e Jesus Berrocal, Instituto de Astronomia, Geofísica e Ciências Atmosféricas - Universidade de São Paulo - Brasil (fabio@iag.usp.br)

Copyright 2004, SBGf - Sociedade Brasileira de Geofísica

Este texto foi preparado para a apresentação no I Simpósio de Geofísica da Sociedade Brasileira de Geofísica, São Paulo, 26-28 de setembro de 2004. Seu conteúdo foi revisado pela Comissão Tecno-científica do I SR-SBGf mas não necessariamente representa a opinião da SBGf ou de seus associados. E proibida a reprodução total ou parcial deste material para propósitos comerciais sem prévia autorização da SBGf

\section{Resumo}

Este trabalho faz parte de um Projeto Temático de Equipe que utiliza vários métodos geofísicos, além de refração sísmica profunda para investigar a Província Tocantins.

Este trabalho de refração sísmica é pioneiro no Brasil por utilizar mais de uma centena de registradores e fontes controladas de energia em três linhas sísmicas com cerca de $300 \mathrm{~km}$ de extensão.

O escopo deste artigo é a linha de refração sísmica L1 Porangatu situada ao norte do estado de Goiás, onde são sugeridos um modelo preliminar de velocidades e uma distribuição de valores para a Razão de Poisson para a região sob esta linha.

O valor da profundidade da descontinuidade de Moho está entre 38 km (Faixa de Dobramentos Brasília) e 42 km (Cráton São Francisco). Os valores da Razão de Poisson indicam que o valo médio fique um pouco abaixo de $0,25\left(\mathrm{Vp}=1,732^{*} \mathrm{Vs}\right)$.

\section{Introdução}

Este trabalho faz parte do Projeto Temático de Equipe "Estudos Geofísicos e Modelo Tectônico dos Setores Central e Sudeste da Província Tocantins, Brasil Central" que utiliza vários métodos geofísicos de investigação, além da refração sísmica profunda. Os levantamentos de refração sísmica profunda efetuados na Província Tectônica Tocantins como parte do Projeto Temático, são pioneiros no Brasil por utilizarem, de forma simultânea, mais de uma centena de sismógrafos (PASSCAL) com registro digital operando na componente vertical e explosões diretas e reversas com hora de origem controlada, programadas exclusivamente para este experimento.

Nesta pesquisa de refração sísmica profunda foram levantadas três linhas de aproximadamente $300 \mathrm{~km}$ de extensão, duas no setor Central da Província Tocantins (linhas L1 - Porangatu e L2 - Cavalcante, na região norte do estado de Goiás) e uma no setor Sudeste (linha L3 Santa Juliana, na região do Triângulo Mineiro). Um esquema das linhas de refração sísmica é apresentado na Figura 1, onde o modelo apresentado neste trabalho corresponde à linha sísmica verde.

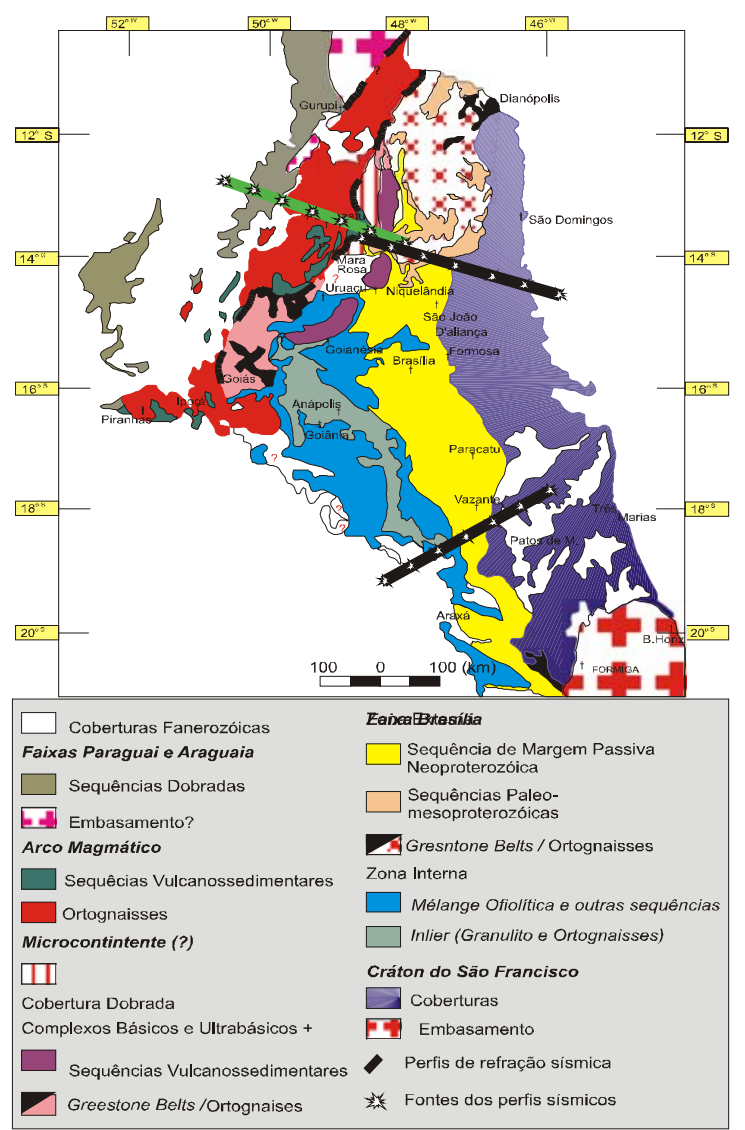

Figura 1 - Mapa geológico da Província Tocantins com a localização aproximada das três linhas de refração sísmica.

Neste trabalho serão apresentados resultados preliminares para as linha L1 - Porangatu utilizando as chegadas das ondas $\mathrm{P}, \mathrm{S}$ e reflexões de ângulo amplo, bem como novas ferramentas de interpretação utilizadas durante o estágio no U. S. Geological Survey no primeiro semestre deste ano.

\section{Descrição da Linha de Refração Sísmica}

A linha de refração sísmica L1 - Porangatu tem aproximadamente $300 \mathrm{~km}$ de extensão, 7 explosões (aproximadamente uma a cada $50 \mathrm{~km}$ ) e 120 pontos de registro, separados a cada $2,5 \mathrm{~km}$, distribuídos ao longo de estradas principais e secundárias. A quantidade de 
explosivos utilizada variou de $1.000 \mathrm{~kg}$ nas explosões dos extremos da linha até $500 \mathrm{~kg}$ para as explosões centrais da linha. (Perosi, 2000).

A linha L1 - Porangatu, situada no setor Central da Província Tocantins, inicia na cidade de São Miguel do Araguaia (próxima ao Rio Araguaia), passando pelas cidades de Porangatu, Minaçu, terminando às margens do Rio Tocantins. Sob o contexto geológico, inicia na Faixa Araguaia, cruza o Arco Magmático de Goiás, terminando na Faixa Brasília (Figura 1).

Os procedimentos metodológicos de campo do levantamento de refração sísmica profunda foram descritos com detalhe em Perosi (2000) e em (Perosi et al., 1999).

\section{Métodos/Ferramentas}

A metodologia consiste na leitura dos tempos das chegadas das ondas $\mathrm{P}$, ondas $\mathrm{S}$ e reflexões de ângulo amplo. O principal (e usual) problema é identificar a chegada da onda $S$, pois a energia foi gerada em explosões e os sinais foram registrados apenas na componente vertical. Por isso, o número de leituras dos tempos de chegadas das ondas $S$ é inferior ao das ondas $P$.

Para auxiliar na identificação da chegada da onda $S$ constrói-se o gráfico da seção sísmica com a chegada da onda $\mathrm{S}$ em uma escala 1,732 vezes maior que o gráfico da seção sísmica com a chegada da onda $P$ e as seções são sobrepostas, dessa forma é possível visualizar os possíveis tempos de chegadas das onda $S$ e ter uma idéia qualitativa a respeito da Razão de Poisson. (Mereu, 2000).

Com os tempos calcula-se a razão $\mathrm{Vp} / \mathrm{Vs}$ e determina-se a razão de Poisson. Uma vez finalizadas as leituras dos tempos de todas as fases escolhidas passa-se para seguinte etapa: modelagem 1D.

A modelagem 1D foi realizada com um programa escrito pelo Prof. Dr. Robert Mereu (Unversity of West Ontário, London, CA). Este programa é escrito em FORTRAN e roda no sistema Linux e a grande vantagem sobre outros programas de modelagem 1D como o TVEL é que se pode modelar ao mesmo tempo as fases $\mathrm{P}$ e $\mathrm{S}$ e também visualizar como seriam as amplitudes esperadas na seção sísmica. Um exemplo de um modelo elaborado com este programa é mostrado na Figura 2.

Com os modelos 1D construídos passa-se para a modelagem 2D com o programa MacRay (Luetgert, 1992) que possui uma interface gráfica para a construção dos modelos agilizando o processo de modelagem. A rotina dos cálculos dos caminhos dos raios é baseada em Cereveny et al (1977).

\section{Resultados}

Até o momento foram construídos os modelos 1D para todos os tiros e iniciou-se a modelagem 2D. O modelo preliminar é apresentado na Figura 3. A profundidade da descontinuidade de Moho se encontra entre 38 e 42 km.

$\mathrm{Na}$ Tabela 1 sugere-se uma distribuição da Razão de Poisson da crosta para região abaixo de cada explosão. Esses valores são preliminares e não estão baseados em todas as medidas realizadas. O objetivo final será fazer um mapa de cores para o modelo, representando a distribuição da Razão de Poisson sob a região.

\begin{tabular}{|l|c|c|c|c|c|c|c|}
\multicolumn{7}{c}{ Tabela 1 - Razões Vp/Vs e Poisson } \\
\hline & EX11 & EX12 & EX13 & EX14 & EX15 & EX16 & EX17 \\
\hline Vp/Vs & 1,739 & 1,712 & 1,720 & 1,719 & 1,724 & 1,734 & 1,732 \\
\hline $\begin{array}{l}\text { Razão } \\
\text { Poisson }\end{array}$ & 0,253 & 0,241 & 0,245 & 0,243 & 0,246 & 0,251 & 0,250 \\
\hline
\end{tabular}

\section{Conclusões}

Até o momento os resultados obtidos foram profundidades da descontinuidade de Moho em torno de $38 \mathrm{~km}$ para região sob a Faixa Brasília e em torno de 42 km para a região sob o Cráton São Francisco, que estão de acordo com as sugeridas por Soares, Berrocal \& Fuck (2003).

\section{Agradecimentos}

À FAPESP pelo financiamento deste projeto e concessão da bolsa de doutorado (processo 00/08463-0). Ao CNPq pela concessão de bolsa-sanduíche (processo 201133/2003-2) para estágio no U.S. Geological Survey, CA, USA. À colaboração do Dr. Walter Mooney (U.S. Geological Survey) e Prof. Dr. Simon Klemperer (Stanford University, CA, USA) coordenador do Program for the Array Seismic Studies of Continental Lithosphere (PASSCAL). Aos professores, técnicos e alunos do IAG/USP e do Observatório Sismológico/UnB que de alguma forma colaboraram com esta pesquisa.

\section{Referências}

Cerveny, V., Molotkov, I. A.. Psencik, I., 1977. Ray Method in Seismology, 214 pp, Charles University Press, Praga, Czech Republic.

Luetgert, J. H., 1992, MacRay - Interactive Two-Dimensional Seismic Raytracing for the Macintosh, Open-file Report 92-356, U. S. Geological Survey, Menlo Park, CA, USA.

Mereu, R. F., 2000, The Complexity of the crust and Moho under the southeastern Superior and Grenville provinces of the Canadian Shield from seismic refraction - wideangle relfection data, Can. J. Earth Sci. 37: 439-458.

Mooney, W. D., Andrews, M. C., Ginzburg, A., Peters, D. A., Hamilton, R. M., 1983, Tectonophysics, v.94: 327348.

Perosi, F. A., 2000, Refração Sísmica Profunda no Setor Sudeste da Província Tocantins, Dissertação de Mestrado, IAG-USP, São Paulo - SP, Brasil.

Perosi, F. A., Berrocal, J., Fernandes, C., Medrado, A. C., 1999, Refração Sísmica Profunda no Setor Sudeste da Província Tocantins: Resultados Preliminares, Anais do VII SNET, Volume único, Sessão 2, p.103, Lençóis - BA, Brasil.

Soares, J. E. P., Berrocal, J. , Fuck, R. A., 2003, The seismic crustal structure beneath Central Brazil: an approach, Resumo expandido deste congresso (8 ICBGS), Rio de Janeiro - RJ, Brasil. 


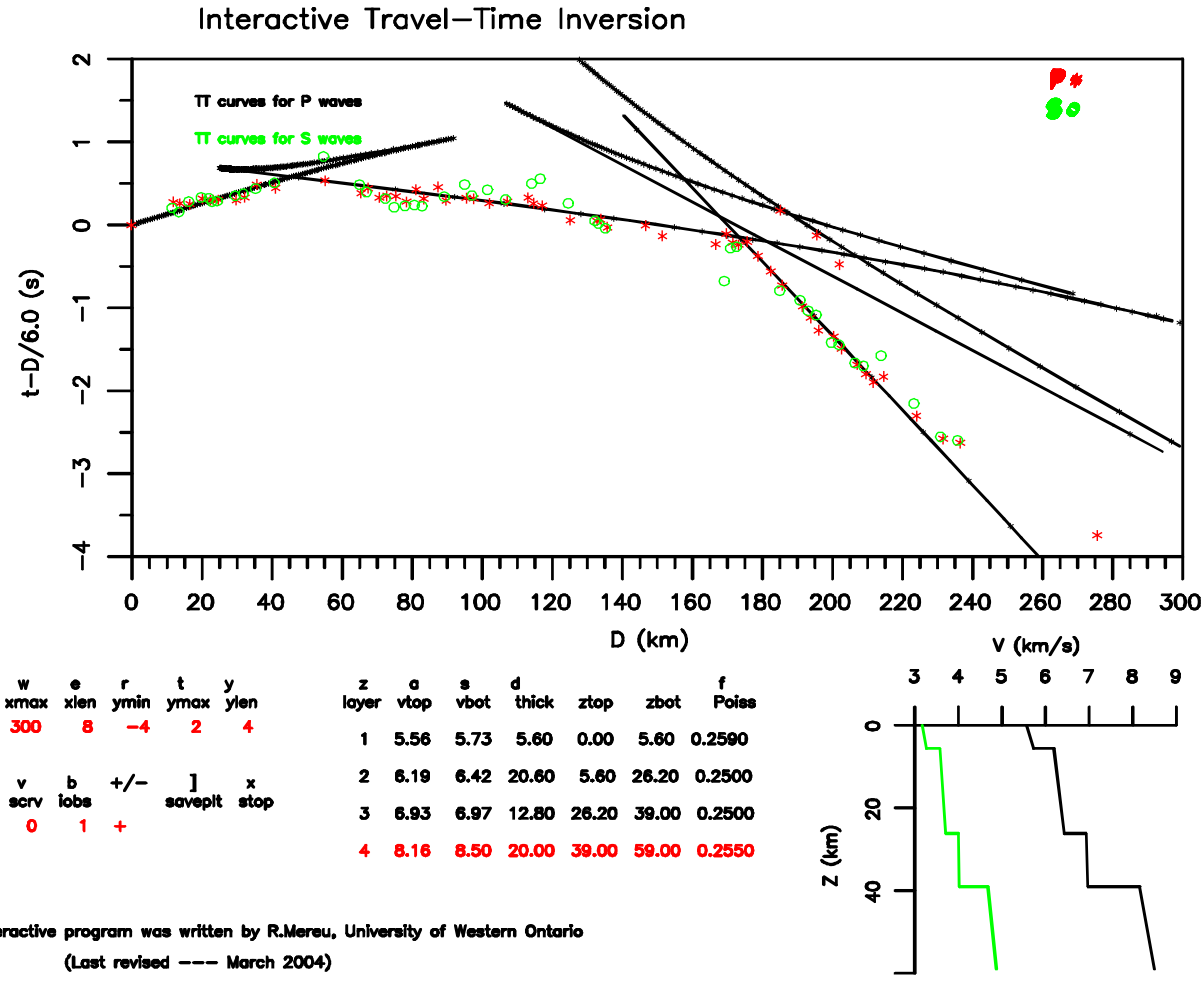

Figura 2 - Modelo 1D referente à explosão ex11. Quanto maior a densidade de pontos nas curvas caminho-tempo espera-se uma amplitude maior da fase no sinal sísmico.

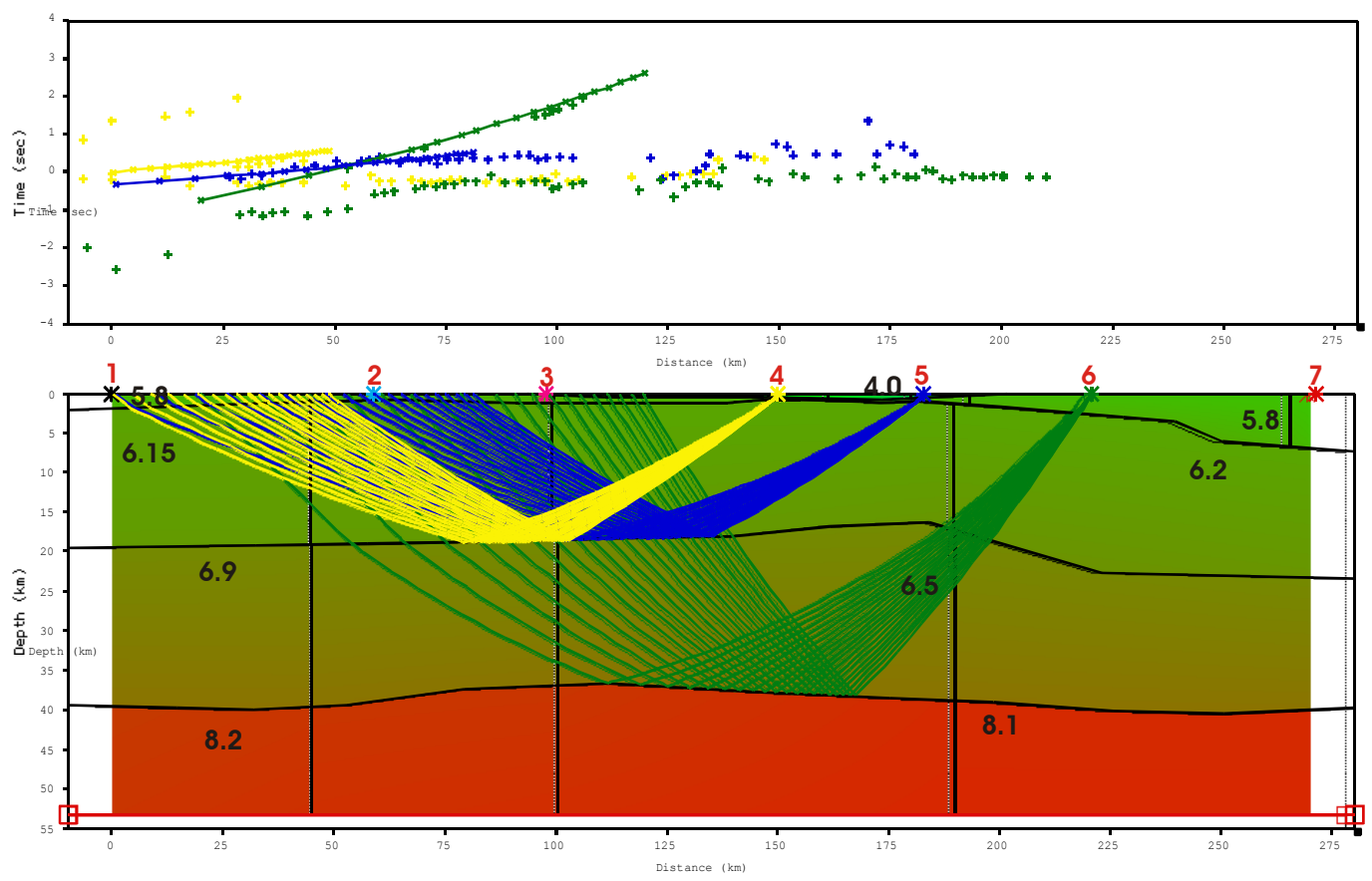

Figura 3 - Modelo preliminar sob a linha sísmica L1-Porangatu. Nesta figura são apenas apresentados os raios das reflexões de ângulo amplo. 